\title{
Similitudes and differences between global warming and COVID-19 crises - Lessons to be learned
}

\author{
Iulian GOLE \\ Bucharest University of Economic Studies, Bucharest, Romania \\ iuliangole@yahoo.com \\ Maria Loredana POPESCU \\ Bucharest University of Economic Studies, Bucharest, Romania \\ popesculrdn@yahoo.com \\ Amelia DIACONU \\ Artifex University, Bucharest, Romania \\ diaconu.amelia@gmail.com \\ Svetlana Platagea GOMBOS \\ Bucharest University of Economic Studies, Bucharest, Romania \\ svegombos@yahoo.com.sg
}

\begin{abstract}
In this article, we try to see if there is a direct link between this health crisis and global warming and if there is something to take away and use at a different level. We are living in complicated times, a sanitary crisis which is followed by an economic one, the amplitude is remained to see, but clearly, both are very damaging. In both cases, being able to rely on the best available scientific knowledge is essential for decision-making. But these cases are quite different because in the case of climate change, apparently, the solution consists in embracing a new social, economic, and energy model. Unfortunately, this aspect is missing from the measures aimed to slow down the COVID-19 pandemic. If certain decisions taken to solve the pandemic seem initially to be directed through the direction of climate protection, others seem rather to going in the opposite direction, so there is no immediate equivalence from one problem to another, and we should not mislead ourselves about possible positive consequences of this health crisis in terms of climate. Nevertheless, perfect communication, coordinated and targeted, clear and honest, has to go hand in hand with the actions taken, to obtain the best and fast results. Despite this situation, we don't have to forget that that humanity is in the middle of another crisis, global warming, which will affect even more, at all levels, not only humankind, and for a longer period.
\end{abstract}

Keywords: health crisis, global warming, climate change.

\section{Introduction}

We wonder why we were able to stop the global economy to fight against the COVID-19 virus, almost one year ago only, when nobody would agree that stopping the commerce, aviation industry, tourism, sports competitions, etc. would ever be possible. But the reality proved again that everything is possible. The answer is because, through the means of communication, we have all perceived the imminence of danger, of immediate death, without solutions, regardless of origin, social level, skin colour, sex, intelligence, etc. It is also due to the perception of the imminent risk, to the fear of not having a bad in a hospital, to the lack of short-term solutions.

There are hundreds of specialists, doctors, or just simple people who transmitted through all channels - TV stations, press, social media networks, etc. the message to stay home, to protect 
ourselves and others, to respect the sanitation rules. It is clear that all this effort was not in vain, the pandemic virus was slowdown at least; now the scientific medical and pharmaceutical community after finding a few efficient vaccines in less than one year is focused to find the best way to distribute equitably all over the world.

On the other hand, for many years, countless researchers, influential people, politicians, actors, etc. have launched calls to react against climate change but, as can be seen up until now, the results are far from being similar. It is up to the media (the press, local and international government agencies, vectors of power) to take an example and use these teachings for the common good of the Earth, and the human race also.

\section{Background and literature review}

Is the Corona virus a consequence of climate change? It is important to remember that COVID19 is a zoonosis, a disease originating from the animal world. Its spread has been made possible by our lifestyles. According to World Health Organisation a zoonosis is a "disease or infection that is naturally transmissible from vertebrate animals to humans. Animals thus play an essential role in maintaining zoonotic infections in nature (WHO, 2020)".

The extension of the human habitat, deforestation, chemical treatment of the soil, provokes more and more interactions between the human species and the wild world. In 2016, the United Nations Environment Program found a sharp increase in zoonosis. 31\% of epidemics such as the Ebola, Zika, H1N1 Swine Flu viruses are linked to deforestation (WEF, 2020). With global warming, the flu is no longer seasonal in the tropics because the normal seasons disappeared; instead, we have two long seasons (dry and rainy) both with high temperatures.

Frequently movements of large numbers of people to new locations (sometimes these spaces are created after deforestation), most of the time under poor conditions of sanitation, exposed the displaced populations being highly vulnerable to biological risks, getting easily ill by disease like malaria, diarrheal and respiratory infections. It is also known that the regions of Wuhan in China, Lombardy in Italy, London in the United Kingdom, and the state of New York in the US are ones of the most airs polluted, so the speedy spreading of the virus is maybe a consequence of the dramatic number of people infected in those places.

Climate change is directly linked to greenhouse gas emissions from human activity which is a real multiplier of biological threats but, for the moment we just can say it was not yet proved to have a direct link between COVID-19 and global worming but certainly it is a direct link of human action against nature. Overall, among the highest risks scaled by World Economic Forum Global risks report 2020, the first 5 out of 10 risks are related to global warming. Maybe this is an explanation about the fact that people generally perceive climate change danger but still, they don't see it as being imminent and deadly - we know the risks and we start to get used to the idea.

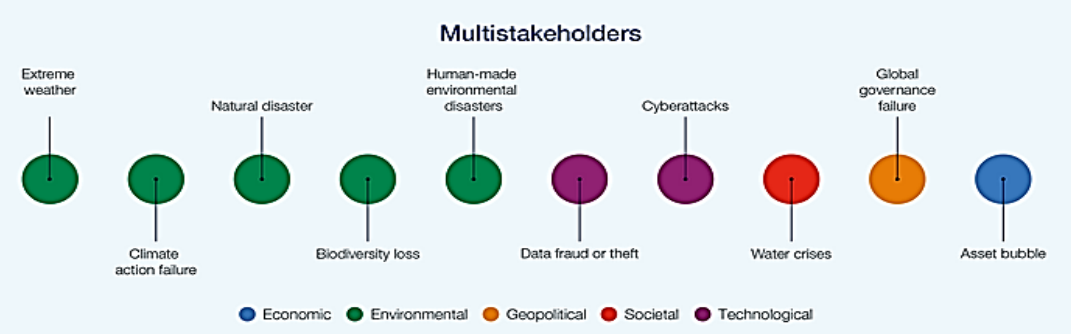

Figure 1. Top 19 risks over the next 10 years. Long-Term Risk Outlook: Likelihood Source: WEF. Global Risk Report. 2020. 


\section{Methodology}

Using descriptive and comparative analysis we exemplify with real data what are the similitudes and antagonisms between COVID-19 and environmental crises. The main research methods used, in order to get results, were surveys, questioners, interviews. The final data were used to build risk evaluation. The types of examinations we have conducted included both ex-ante and ex-post assessments and we needed qualitative as well as quantitative data.

For assessing measures, we used a scenario and SWOT. Multiple regression analysis was

PICBE |

436 also used as a forecasting method to determine the CO2 evolution over time.

We started our analysis by explaining why the pandemic crisis could have such an efficient reaction from citizens while the problem of climate change, even though is revealed for a longer time with heavier consequences, doesn't seem to interest people at the same level.

We analysed data from different sources to expose what is the degree of urgency of global warming and why the governments may not be interested in approaching this issue. We also showed how big is the financial effort that our generation has to pay in order to eliminate fossil energy and how this amount is compared with the pandemic cost.

\section{Results and discussions}

Despite the prior engagements assumed by most of the countries at the end of COP 21, still, the evolution regarding GHG emission is not satisfying. As we will see from the prognosis, there are few chances to obtain the results unless we will not succeed in decoupling the economy from fossil energy. The measures taken to stop the extinction of pandemics brought benefits for the global warming problem but this cannot be a satisfying solution in long term and we will see why. We also talk about the total cost of using $100 \%$ of renewable energy.

Although it also requires urgent action, climate change is a new reality to which we will have to adjust. The problem is that, in contrast to the pandemic, there are no temporary measures that could be removed after the "critical situation" has passed. And even if the negative consequences of global warming and the number of potential victims resulting from the ecological disasters are immeasurably greater than in the case of the new coronavirus, this damage remains for the time being quite hypothetic, when we count the victims caused by COVID-19 each day. We probably could say the epidemic is a sort of climate change in a compressed phase, over time.

Nevertheless, in both situations, the necessity to take firm political decisions in advance is essential to limit the consequences. In both situations, it is absolutely necessary to build and explain the decisions with the help of the strongest, safest, and concluding available scientific data. And in both situations, the behaviour of billions of people must be synchronised, systemised, and changed at the same time in order to hope to solve the problem, which requires strong political measures. Also, in both cases, perfect communication, coordinated and targeted, clear and honest, has to go hand in hand with the actions taken, to obtain the best and fast results.

From a social and psychological point of view, the parallels and divergences between the COVID 19 crisis and the climate emergency it is also a challenge. It seems necessary to reflect on the reasons currently pushing the vast majority of individuals to accept strict measures to protect against the virus but would most certainly not accept them to limit climate change.

Apart from the temporary aspect of current measures, which has already been widely discussed, it seems important to consider the notion of psychological distance, which is defined as space (temporal, geographic, social, and hypothetical) perceived between a phenomenon and yourself. At the start of 2020, the COVID 19 was still psychologically distant; not only because 
its existence was limited to another continent, but also because it touched (except in very rare cases) people whom we did not know and the "exit" from Asia was only one scenario among those possible but initially few people believed in it (maybe because in the SARS case in 2003, only Canada, Hong Kong, Chinese Taipei, Singapore, and Hanoi in Viet Nam were affected). As the distance narrowed, the acceptance of the proposed measures increased, and voices appeared to demand more stringent ones.

But even if these resemblances are important aspects to be considered for future PICBE | decisions, we should not forget that there is a huge distance between the capacity to foresee the spread of the actual pandemic (it seems that when our governments are confronted with this situation, the democratic system starts to lose power) and, that of anticipating by a long period (decades or hundreds of years) a fundamental change in our climate.

Of course, the pandemic issue is huge and urgent, and many people all over the world, including from developed and reach countries and not only the poorest ones, are suffering greatly because of the sickness. But this is a different type of problem when we comparing with climate change, which is a catastrophe that evolves daily.

The COVID-19 epidemic is rather a standardised group issue (the immediate solution is to stay home and respect the sanity rules); climate change is an intergenerational collective action problem with multilevel parts of the solution. In the case of climate change, the consequences of global warming are becoming more evident year after year, unfortunately, the pieces of evidence will be seen and felt everywhere, and especially in the most vulnerable countries, the future is no good at all.

The fact that the problem of climate change is known already for decades but still it is perceived as without imminent danger for most people, it pushes us through a certain nature to procrastinate. Somehow it is natural to see that if we take into consideration that today our society is built on a perpetually growing economy and most of the necessary energy comes from fossil fuels.

Having in mind all these aspects we should not believe that once a vaccine or a cure against the coronavirus, states would suddenly decide to take further actions and treat the global warming problem with similar vigour.

The consistent difference between efforts to fight the COVID-19 pandemic and those made to avoid a global climate disaster is clear for everybody that has an interest in the subject. Still, the effects of social distancing together with measures to reduce greenhouse gas emissions have also been widely covered in the press. However, even ignoring the many personal tragedies caused by the new coronavirus for a moment, it is obvious that we have huge problems to face.

Greenhouse gas emissions in 2020 will certainly drop by a few percent as a result of the epidemic (those from China fell by around $25 \%$ during February, and demand for electricity in Italy would have dropped by $18 \%$ ) but this remains little compared to what it would take to achieve the objectives of the Paris Agreement (Myllyvirta, 2020). To reach the Paris temperature target, it has been estimated that the amount of carbon remaining after deducting past emissions is between 150 and 1,050 Gt of CO2. At current annual emission rates, the lower limit of this range will be exceeded in four years and the average point (600 Gt of CO2) in 15 years. Emissions should drop to zero right after the $\mathrm{CO} 2$ budget is depleted (Figueres et al. 2017).

Of course, these graphics are an approximation, it is impossible to measure accurately all the indicators but at least, it demonstrates again what was already scientifically proven, that economic activity is yet today largely based on fossil fuels. 


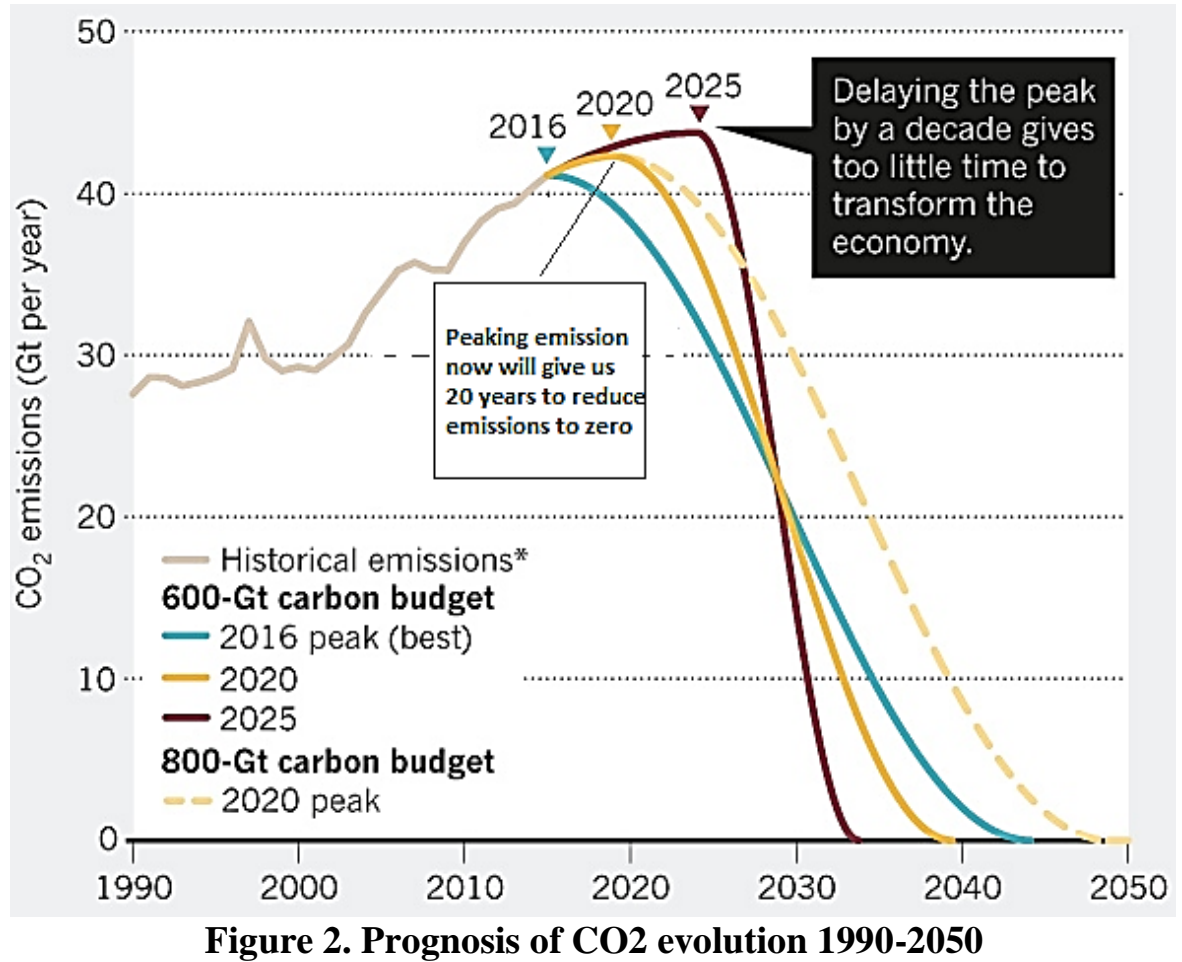

PICBE |

Source: Figueres, 2017.

Letting people believe that the actions against climate change may be equal to those against the new coronavirus may be ineffective. Even though several resemblances between pandemic and global warming crises were acknowledged, other notable differences between both problems were observed and we have to be aware of this. For sure the most obvious is their duration and the time when started. A difference is also the fact that the climate change issue will be reduced by changing the actual style of life, by shifting our source of energy, by rethinking the global economy, in any case not just by stopping all activities. If the economy was stopped for 1,5-2 months in the spring of 2020 and late autumn in some areas with countless negative effects, impossible even to imagine what would happen if it will be shut down forever.

Finally, from a political perspective, there are low chances that the COVID-19 pandemic could bring positive aspects to the fight against global warming. It is almost sure that the moment when the pandemic is finished, the main preoccupation of political leaders running the governments will only be to restart the economy. We can therefore fear not only a rebound effect in terms of greenhouse gas emissions but also that the climate changes issue will be less important on the politician's agenda.

It is time that the organisation fighting against climate change rise up their voices. It is a good moment that the post-crisis and economic revitalization measures to serve as a trampoline for an urgent and essential energy transition. The battle for climate change will continue day after day, in the streets and the elections, not by counting on a sudden awakening to the reality of the political class. Communication has to be done direct, actively and targeted through all the media, socialising networks, blogs, and other possibilities in order to get on board more and more people, not only to inform but to make them change their consumption behaviours. 
But climate change is more than a simple problem. Although it also requires urgent action, the climate change issue becomes rather the new standard of life and people will have to adapt their existence to that. Contrary to the pandemic, the problem cannot be solved by taking short-term decisions, which could be cancelled when the situation has improved.

Shutting down an economy will have as a direct consequence, without doubt, the reduction of GHG emissions, but this can be only a short term policy. Lowering the spreading of the virus consists in limiting social life but the first consequence is that many economic sectors (cinema, restaurants, culture, places of conviviality, catering, trade, sports, etc.) will suffer because of lack of customers. Every person is reducing its travelling and will try to spend more time at home, tourism is not recommended if not forbidden with some exception. The remaining problem is that still there is no essential rethinking of the clean energy solutions or the consumption habits - even though many people are in lock-down it looks the business continues as usual.

In order to have positive results in the fighting against climate change, it is necessary a new approach - based on structural changes of economies that can transform them and bring sustainability over the years. There is no other way of decarbonising our world than by minimising fossil fuel energy consumption. There is a strong need for conversion of the energy system through renewable. But nothing stands against the way of maintaining, or even increasing, social contacts if we can still be reasonable in our energy consumption; at the end of the day, nothing can replace a warm hug or a kiss. Everyone can easily agree that being part of a sustainable society is healthier and nice, in the long term, than living in a society where epidemic risks may become frequent.

It is clear that in the case of global warming the solution can only be a new economic model based on new sources of clean energy. This aspect is totally out of the side in the case of measures taken to slowdown the COVID-19 pandemic. If some of the measures against the pandemic seem, without being too picky, are moving in the same sense as those against global warming (for example the reduction of plane flights, the democratization of videoconferences), others seem rather go in the opposite direction (avoid public transport and therefore promote individual mobility), therefore there is no immediate equivalence from one problem to another, and we should not mislead ourselves about possible positive consequences of this health crisis in terms of climate.

Taking into account all the arguments presented up until now, it looks that one of the most interesting take away from this pandemic is the occasion of thinking and reflecting on the subject which, if it is used efficiently, can bring greater contribution in the future. This is undoubtedly an unexpected occasion to take a break for a second and put the right questions about the actual economic model and our consumer habits. Another point to reflect on is what the contradictory factors are that climate change action is so timid.

Probably one of the main important is the way we understand our relationship with next generations (why should we treat them more protective compared with ourselves, family, friends, neighbours?-is this only a meter of selfishness or is something more than that?) but also the process of building the decisions, the why we trust and use scientific information and knowledge (climatologists have been trying already during decades to make us understand about the terrible effects of climate change but as we can see without remarkable results - at least from the political perspective.

Today almost every politician speaks about the protection of the people less fortunate among us, and this aspect is somehow quite legitimate, especially during the pandemic, but a 
similar approach was used during the first alerts regarding climate change. It is clear that the moment of moving forward, passing from words to facts, has arrived.

We are facing a situation that was not seen in the recent past - we see governments taking measures that could look undoable in a regular situation and we can see that actually, people are respecting them. It means that in fact, the context is important in obtaining the results.

We are witnessing the treatment of this crisis in a spectacular comeback of the political, which we thought was irreparably subordinated to economic issues. On the contrary, the pandemic proves that even democratic governments could take hard measures when the health of people is on the table. It would be useful to think about how to replicate this process policy implementation in the field of global change. We saw almost everywhere opposition leaders accepting the government's demands without complaints, without thinking too much at the first election term and, the business leaders following the rules strictly.

The current crisis notably makes it possible to put into perspective the costs of the transition to renewable energies. The report "Impacts of Green New Deal Energy Plans on Grid Stability, Costs, Jobs, Health, and Climate in 143 Countries", which revealed its details in the journal One Earth in 2019, presents specific actions that the 143 countries (which produced $99.7 \%$ of $\mathrm{GHG}$ ) can transform theirs energy sources to renewable provenance by 2050 .

The cost of the process of shifting from the actual energy system to a new one, where all sources are green, by 2050 , has been estimated at a global of $\$ 73$ trillion, but this amount of money will be recovered in approximately 7 years. "Worldwide, clean energy WWS (windwater-solar) reduces energy needs by $57.1 \%$, energy costs from $\$ 17.7$ to $\$ 6.8$ trillion/year (61\%), and social (private plus health plus climate) costs from $\$ 76.1$ to $\$ 6.8$ trillion/year (91\%) at a capital cost of $\sim \$ 73$ trillion", according to the same report. The research concluded that a switch from our daily business in terms of energy to a neutral-carbon society will bring into the market 28.6 million extra jobs compared with the actual situation, if people keep doing business as usual, in other words, if we keep continuing to rely on fossil fuels.

We should remind here that global GDP in 2017, according to the latest estimation from the World Bank and detailed by Jeff Desjardins in 2018, was approximately $\$ 80$ trillion. If we compare with the necessary amount to switch the production of energy from fossil to renewable we can see that is roughly the same.

Now, let's compare these figures with those amounts announced as support for the economy unlocked by some countries as a support for the people affected by coronavirus pandemic (40 billion $€$ in the case of Switzerland, 100 billion from Japan government, 820 billion in Germany and 2 trillion for the USA, and it's probably not over - these amounts were announced at the time when the paper was written, sure the amounts will grow up consistently once the time is passing and the consequences are visible). It is obvious that there is a huge difference.

In any case, the estimated losses calculated by IMF in April 2020, are around $\$ 9$ trillion and certainly, the amount will go higher after the second wave and as time goes by. 


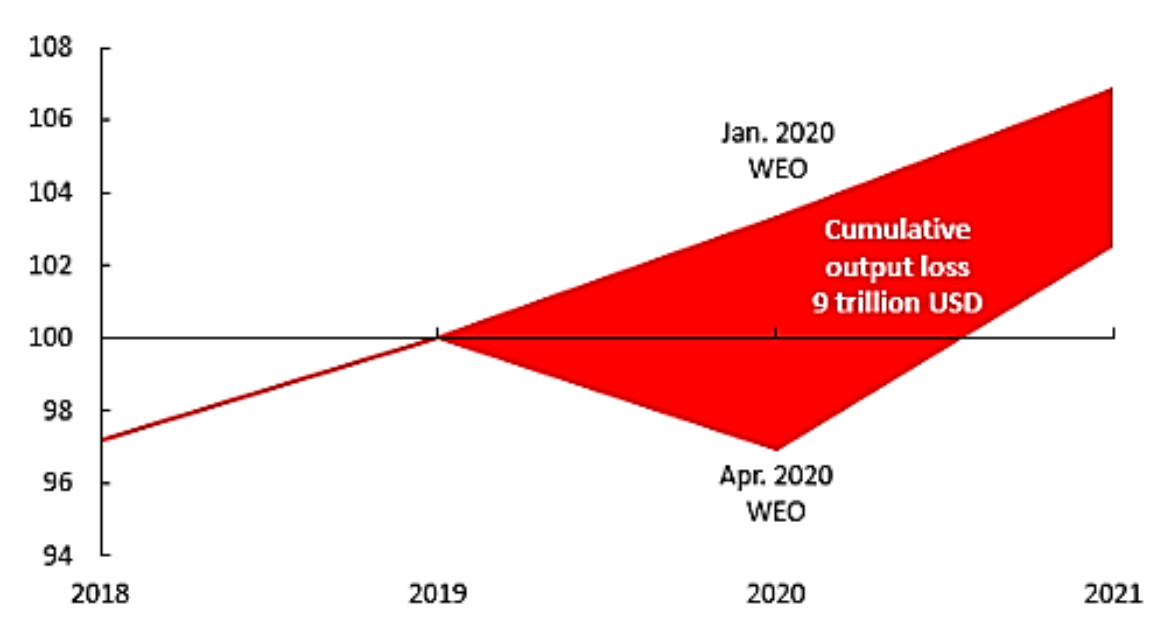

PICBE |

Figure 3. Output losses - Global real GDP level

Source: IMF, World Economic Outlook, and IMF staff calculations. 2020.

At the same time, we have to admit that the costs of combating climate change are undoubtedly annual expenses, but these expenses are made in order to help people permanently and definitely could avoid the death of a large number of people or in any case would improve the lives of billions (not to mention about the benefits for the nature and other living things). This money will also bring new wind into the economy sails, not to mention the benefit of stopping an irreversible process of climate destruction. On the other hand, the labour market will also register a positive impact as a result of these new investments; new jobs will be created, new opportunities for the entrepreneurs. The results will be seen naturally in the long term rather than short. If we think to the next generation, most probably this is an effort that could give them higher chances for future, better standards of life. The reach and industrialised countries have not only the power and capabilities to do this but also an obligation - thinking the way that some of them benefitted in the past; after all, is an expenditure equivalent with less than 1 year of global GDP, and the effort can be made during an extended period.

We can also consider that the post pandemic recovery plans have to be accompanied by conditions in a few economic sectors (hospitality, transport, energy, heavy industry) in order to start to seriously affect the curve, not to the progression of the virus this time, but CO2 emissions.

Some attempts are made but for the moment without too much success. For example, 8 US Democratic senators propose to link the $\$ 60$ million aid to the future carbon emissions performance of US airlines as a part of the rescue package aimed to save the aviation companies because of the coronavirus crisis. "Given the large carbon footprint of commercial aviation, requiring reductions in carbon emissions would represent a major step in curbing our nation's greenhouse gas emissions. If we give the airline and cruise industries assistance without requiring them to be better environmental stewards, we would miss a major opportunity to combat climate change and ocean dumping" (Greenair, 2020). Unfortunately, the proposal was rejected but at least we see there is a willingness to use the corona crisis to fix the global warming problems. Meanwhile, the leader from the White House changed; it remains to see what the consequences on the environmental issue are.

A large-scale presentation of correct and concise information is needed, adapted to different levels of perception so that every citizen or organization to be aware of the dangers that await us in the not too distant future as a result of our actions or inactions. NGOs need to put 
more pressure on governments, but at the same time they need to gain the credibility of citizens in terms of funding sources, the truthfulness of the information presented, and the credibility of communicators.

Governments, in turn, are primarily responsible for implementing environmental policies. And they need to communicate better, more concretely, to express clear objectives that can be verified by the population. It must be understood that although we will have a cost that will be upheld unequally by different sections of the population, the future benefit is immeasurable, even if future generations will be the ones who will enjoy it more. There is already a cost of inaction and we all feel it through the degradation of wildlife, the rise in extreme temperatures in the warm seasons, the disappearance of spring as a season, prolonged drought and fire bushes, problems with water supply, etc. If it is permanently communicated and explained with concrete and verifiable data, surely humanity can make this effort, and economic, material, and human losses will be dramatically reduced in the coming years.

In all cases, it depends on the officials and the civil society organisations to check if the healing after the pandemic is not bringing a weakening of the fighting against climate change. There is a certain risk that the countries will come back to the same habits regarding energy consumption: cheap and fast, in other words, to exploit fossil fuel in order to obtain a fast economic recovery.

As always, there is the duty of environmental NGOs and other organisations to maintain alive the dynamics registered during 2019, so that the subject of climate change to be on top of the government's priorities.

\section{Conclusions}

Even if recent scientific data bring it "psychologically" closer to us, climate change is still distant, and sometimes confused, when several competing scenarios are presented to the general public. When it is perceived to be as close and as precise as the prospect of being contaminated by COVID-19, it will, unfortunately, be too late to act. We cannot, therefore, rely on the same mechanisms that underpin acceptance of the current measures.

In this paper, we demonstrated that the issue of climate change is more stringent than ever, and the damaging consequences are imminent. The risk assessment over the next 10 years revealed that half of them are related to global warming. Although the measures to contain the pandemic helped to some extent, the solution for fighting global warming cannot be similar. People need a developed economy in order to maintain an acceptable standard of living but we have to recreate new habits in our life and a better way of doing business, to finally transform the global economy into a long term sustainable one. Only by moving from massive fossil energy consumption to a balanced utilisation from renewable sources, we can reach to the main objective of decarbonising.

We presented also what the cost of the energy transition might be and why this process can be done if there is a global consensus. We compared this cost with money spent in order to help the economy after the pandemic and we saw that there is a huge difference but the results would be beneficial for all, and not only for humans. To succeed all forces need to unite, from political governments and international organisations to civil society, NGOs, or simple people.

The way we communicate is very important, the desire to fight against damaging the biosphere, in particular by accepting significant restrictions on individual freedom, requires a certain level of abstraction in the way in which we represent climate change (as a global and 
polymorphic phenomenon for example); it is not only for oneself, or one's loved ones, that one must act, but for future generations here and elsewhere, for non-human species, etc. The current crisis teaches us to limit our gestures, to reduce (indirectly) our footprint, for the good of all, even if the probability that our existence to be in danger is limited.

There are similarities between the two crises but the long-term consequences and solutions are completely different. Reality has shown, however, if there is a will, there is a solution for every problem, including for COVID-19. Hopefully, these lessons will be learned.

\section{References}

WHO (2020). Zoonoses, Retrieved from https://www.who.int/topics/zoonoses/en/.

World Economic Forum (2020). How biodiversity loss is hurting our ability to combat pandemics. Retrieved from https://www.weforum.org/agenda/2020/03/biodiversity-lossis-hurting-our-ability-to-prepare-for-pandemics/.

WEF (2020). Global Risk Report. Retrieved from https://reports.weforum.org/global-risks-report2020/shareable-infographics/.

Myllyvirta, L. (2020). Analysis: Coronavirus temporarily reduced China's CO2 emissions by a quarter. Retrieved from https://www.carbonbrief.org/analysis-coronavirus-hastemporarily-reduced-chinas-co2-emissions-by-a-quarter.

Figueres, C., Schellnhuber, H.J., Whiteman, G., Rockström, J., Hobley, A., and Rahmstorf, S. (2017). Three years to safeguard our climate. Nature 546(7660), 593-595. Retrieved from https://doi.org/10.1038/546593a.

Desjardins, J. (2018). The $\$ 80$ Trillion World Economy in One Chart, Retrieved from https:// www.visualcapitalist.com/80-trillion-world-economy-one-chart/.

Greenair (2020). Efforts to link US airline rescue package to carbon targets resisted as industry faces unprecedented times. Retrieved from https://www.greenaironline.com/ news.php?viewStory=2684. 